Braz J Med Biol Res, February 2012, Volume 45(2) 139-146

doi: 10.1590/S0100-879X2012007500012

Effect of lipoarabinomannan from Mycobacterium avium subsp avium in Freund's incomplete adjuvant on the immune response of cattle

S.B. Colavecchia, A. Jolly, B. Fernández, A.M. Fontanals, E. Fernández and S.L. Mundo

The Brazilian Journal of Medical and Biological Research is partially financed by

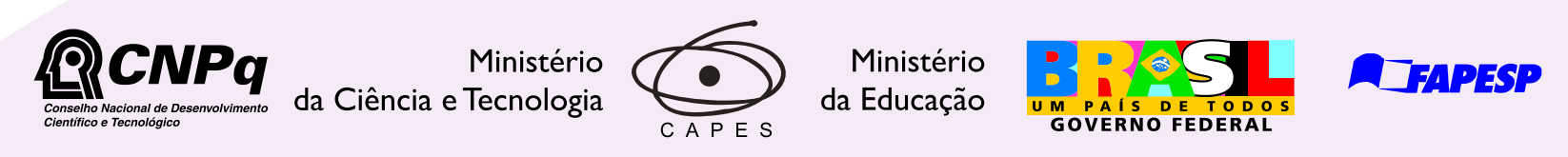

Institutional Sponsors
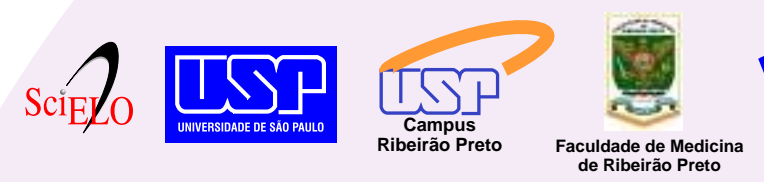

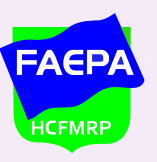

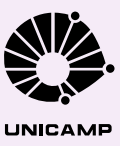

SHIMADZu

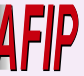

Associaçăo
Fundo de Incentivo
à Pesquisa

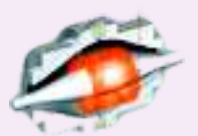

UNICAMP

lore High - Performance MS Orbitrap Technology analitica Thermo 


\title{
Effect of lipoarabinomannan from Mycobacterium avium subsp avium in Freund's incomplete adjuvant on the immune response of cattle
}

\author{
S.B. Colavecchia ${ }^{1}$, A. Jolly ${ }^{1}$, B. Fernández¹, A.M. Fontanals ${ }^{1}$, \\ E. Fernández ${ }^{2}$ and S.L. Mundo ${ }^{1}$ \\ ${ }^{1}$ Inmunología, Facultad de Ciencias Veterinarias, Universidad de Buenos Aires, \\ Ciudad Autónoma de Buenos Aires, Argentina \\ ${ }^{2}$ Clínica de Rumiantes, Facultad de Ciencias Veterinarias, Universidad de Buenos Aires, \\ Ciudad Autónoma de Buenos Aires, Argentina
}

\begin{abstract}
The aim of the present study was to determine whether lipoarabinomannan (LAM), in combination with Freund's incomplete adjuvant (FIA), was able to improve cell-mediated and antibody-mediated immune responses against ovalbumin (OVA) in cattle. Twenty-three calves were assigned to four treatment groups, which were subcutaneously immunized with either OVA plus FIA, OVA plus FIA and LAM from Mycobacterium avium subsp avium, FIA plus LAM, or FIA alone. Lymphoproliferation, IFN-Y production and cell subpopulations on peripheral blood mononuclear cells before and 15 days after treatment were evaluated. Delayed hypersensitivity was evaluated on day 57 . Specific humoral immune response was measured by ELISA. Inoculation with LAM induced higher levels of lymphoproliferation and IFN-y production in response to ConA and OVA $(P<0.05)$. Specific antibody titers were similar in both OVA-immunized groups. Interestingly, our results showed that the use of LAM in vaccine preparations improved specific cell immune response evaluated by lymphoproliferation and IFN-y production by at least 50 and $25 \%$, respectively, in cattle without interfering with tuberculosis and paratuberculosis diagnosis.
\end{abstract}

Key words: Lipoarabinomannan; Cattle; Immunomodulation; Mycobacterium avium subsp avium

\section{Introduction}

Protection against infectious diseases may require a cell-mediated immune response (CMIR) and/or an antibodymediated immune response (AMIR), depending on the agent. Adjuvants have been used since the early 1920's (reviewed in Ref. 1) to improve vaccine efficacy through the enhancement of a specific CMIR and/or AMIR. Since adjuvants may cause a number of adverse consequences, either locally at the injection site or systemically, these reactions must be minimized for the development of new safer vaccines (2). The mechanisms of action by which adjuvants promote an increased immune response may be: the depot effect, antigen presentation, antigen distribution or targeting and immune activation/modulation, and CD8 cytotoxic T lymphocyte induction $(1,2)$.

Microbial cells, their components, or chemically modified microbial products have historically been used as adjuvants in vaccines. Freund's complete adjuvant (FCA) is a waterin-mineral-oil adjuvant containing heat-killed Mycobacterium tuberculosis that stimulates both a CMIR and an AMIR and was considered to be the gold standard adjuvant for many years (2). However, FCA causes severe lesions at the site of injection (3) and cannot be used in commercial herds since mycobacterial antigens may interfere with the in vitro and in vivo diagnosis of tuberculosis. The same effect is detected with the use of Mycobacterium sp walls or protein antigens in experimental immunology and vaccination procedures $(4,5)$. On the other hand, Freund's incomplete adjuvant (FIA), which uses mannide monooleate into which the antigen is emulsified, has been shown to increase antibody responses more than other adjuvants, such as aluminum salts, in humans and animals $(6,7)$. FIA has been well tolerated, since toxicity is controlled by the

Correspondence: S.L. Mundo, Inmunología, Facultad de Ciencias Veterinarias, Universidad de Buenos Aires, Chorroarín 280, (1427) Ciudad Autónoma de Buenos Aires, Argentina. Fax: +54-11-4524-8480. E-mail: smundo@fvet.uba.ar

Received April 24, 2011. Accepted January 16, 2012. Available online February 3, 2012. Published February 17, 2012. 
use of high-grade oils and purified surfactants. Besides, several studies using Marcol 52, Arlacel C, and Tween 80 as oil adjuvants in a Tritrichomonas vaccine have detected an increase in resistance to infection in immunized cattle (8). One disadvantage of FIA is that it does not potentiate the CMIR, which is critical for the control of many infections $(7,9)$. The inclusion of purified components of mycobacteria could be an alternative to improve these responses.

Lipoarabinomannan (LAM) is an important component of the cell wall of mycobacteria. It is a conserved mannosylphosphatidyl-myo-inositol that possesses a mannan core and a branched arabinan polymer, which in some cases is decorated with a terminal cap motif (10-12). LAM can be classified into three major structural families: ManLAM, present in pathogenic strains (including Mycobacterium avium subsp avium; Maa) with a short capping of mannoses; PILAM, present in fast-growing non-pathogenic strains with inositol phosphate caps, and AraLAM, present in $M$. chelonae, which does not have capping $(12,13)$. Modulation studies with LAM have been carried out in vitro with mouse (14) and human cells (15), and in vivo in mouse models $(16,17)$, using different doses and immunization protocols, indicating that LAM and different mycobacteria induce a Th1 biased response in allergic and parasitic diseases.

The aim of the present study was to determine whether LAM, in combination with FIA, is able to improve CMIR and AMIR against ovalbumin (OVA) in cattle. To our knowledge, this is the first study about the immunomodulatory effects of LAM on the immune response in a bovine model. The results could be useful for future applications, such as the development of new vaccines in cattle.

\section{Material and Methods}

\section{Bacterial strain \\ Maa (R4 ER strain, kindly provided by Dr. A. Bernardelli, Servicio Nacional de Sanidad Animal, Argentina) was grown in Dorset Herley medium for 8 weeks, heat-inactivated and lyophilized for LAM extraction and vaccine preparation.}

\section{Preparation and characterization of LAM extract}

LAM was extracted from $91.8 \mathrm{~g}$ Maa as previously described (18). Briefly, crude LAM was purified on a $100 \mathrm{x}$ $25 \mathrm{~cm}$ Sephadex G-200 column equilibrated with PBS at a flow rate of $25 \mathrm{~mL} / \mathrm{h}$. Fractions of $3.5 \mathrm{~mL}$ were collected and examined for carbohydrate content by the phenol-sulfuric acid method using glucose as standard (19) and for protein content by the Bradford method using bovine serum albumin as standard (20). LAM-containing fractions were identified by ELISA using a monoclonal antibody $(\mathrm{mAb})$ specific for LAM of M. tuberculosis (mAb CS-35, kindly provided by Dr. J. Belisle, Colorado State University, Fort Collins, CO, USA). Fractions that strongly reacted with $\mathrm{mAb} C \mathrm{CS}-35$ were pooled, concentrated by ultrafiltration and characterized by SDSPAGE and immunoblot as previously described (18).

\section{Animals, groups and immunization protocols}

Twenty-three 6-month-old Holstein calves from tuberculosis-free accredited herds were kept on a natural farm in the Pampas region of Argentina throughout the experiment. Calves were randomly assigned to one of the following experimental groups: OF $(\mathrm{N}=7)$, which received $1 \mathrm{mg}$ OVA (Sigma Chemical Co., USA) dissolved in $1 \mathrm{~mL}$ PBS, pH 7.4, and emulsified in $1 \mathrm{~mL}$ FIA (Sigma-Aldrich Co., USA); OFL $(\mathrm{N}=8)$, which received $1 \mathrm{mg}$ OVA and 1 $\mathrm{mg} \mathrm{LAM}$, both dissolved in $1 \mathrm{~mL}$ PBS and emulsified in 1 $\mathrm{mL}$ FIA; FL $(\mathrm{N}=3)$, which received $1 \mathrm{mg} L A M$ dissolved in $1 \mathrm{~mL} P B S$ and emulsified in $1 \mathrm{~mL} F I A$, and $F(N=5)$, which received $1 \mathrm{~mL}$ PBS emulsified in $1 \mathrm{~mL}$ FIA. Calves were inoculated subcutaneously on days 0,21 , and 42 on the left scapular region. The experiment was performed with the approval and under the supervision of the Institutional Committee for the care and use of experimental animals of Facultad de Ciencias Veterinarias, Universidad de Buenos Aires.

\section{Proliferation assays}

Proliferation assays were performed on days 0 (preimmunization) and 57 (15 days after the third immunization). PBMC were isolated from heparinized blood by density gradient centrifugation using Histopaque 1077 (Sigma-Aldrich Co.) according to standard techniques (21). Lymphoproliferation assays were performed in U-shaped 96-well plates (BD Biosciences, USA) containing $100 \mu \mathrm{L} /$ well PBMC $\left(0.5 \times 10^{6}\right.$ viable cells/well) in RPMI 1640 (Invitrogen Corporation, USA) with $10 \%$ fetal calf serum (FCS, Invitrogen Corporation). Cells were cultured in $5 \% \mathrm{CO}_{2}$ at $37^{\circ} \mathrm{C}$ and stimulated for 4 days with $2.5 \mu \mathrm{g} / \mathrm{mL}$ concanavalin A(ConA; Sigma-Aldrich Co.), $250 \mu \mathrm{g} / \mathrm{mL}$ OVA or $250 \mu \mathrm{g} / \mathrm{mL}$ LAM. Non-stimulated wells were incubated only with RPMI as control, and $0.5 \mu \mathrm{Ci}$ methyl-[ $\left.{ }^{3} \mathrm{H}\right]$-thymidine (New England Nuclear Radiochemicals, USA) was added to each well. Twenty hours later, cells were harvested onto Whatman GF/A paper and the incorporated radioactivity (counts per minute, $\mathrm{cpm}$ ) was measured by liquid scintillation counting (beta counter 1214 Rackbeta, Vallac; Pharmacia, Finland). Experiments were run in triplicate and the stimulation index (SI) was calculated as mean cpm of stimulated wells/mean cpm of non-stimulated wells. A control of LAM toxicity was made by comparing the proliferation response to ConA and ConA plus LAM and no significant differences were detected between these treatments.

\section{IFN-Y production}

IFN-y ELISA was performed according to manufacturer specifications (duoset ELISA development system, R\&D Systems Inc., USA). Briefly, 96-well plates (Immulon 2HB, Dynex Technologies, USA) were coated with $100 \mu \mathrm{L}$ antiIFN-y mAb (R\&D), $2 \mu \mathrm{g} / \mathrm{mL}$ in PBS overnight at room temperature. The plates were washed three times and blocked with $100 \mu \mathrm{L}$ PBS containing $0.05 \%$ Tween 20 and $0.05 \%$ 
sodium azide for $2 \mathrm{~h}$ at room temperature. After washing, $100 \mu \mathrm{L}$ of the culture supernatants of the proliferation assays or recombinant IFN-Y (R\&D, to construct a reference curve) was incubated for $2 \mathrm{~h}$ at room temperature. Then, $100 \mu \mathrm{L}$ biotin labeled-anti-IFN- $\gamma$ (R\&D), $0.4 \mu \mathrm{g} / \mathrm{mL}$, was added to each well and the plates were further incubated for $2 \mathrm{~h}$ at room temperature. One hundred microliters of HRP-conjugated streptavidin (R\&D) 1:200 was added and incubated for $2 \mathrm{~h}$ at room temperature. After subsequent washes, plates were developed using ortho-phenylenediamine dihydrochloride (Sigma-Aldrich Co.) in citrate buffer (Sigma-Aldrich Co.). Absorbance at $490 \mathrm{~nm}$ was measured with an OpsysMR spectrophotometer (Dynex Technologies).

\section{Flow cytometry}

Blood leukocytes were labeled for flow cytometry using a single staining procedure. A total of $1 \times 10^{6}$ viable cells in $100 \mu \mathrm{L}$ PBS were labeled in round-bottom microplates (GBO, Greiner Bio One Inc., USA) with FITC-conjugated goat anti-bovine IgG (Sigma-Aldrich Co.), mouse lgG1 anti-bovine CD4 (CACT138A, VMRD, USA), mouse IgG1 anti-bovine CD8 (BAT82A, VMRD), mouse IgG1 anti-bovine CD25 (CACT116A, VMRD), and FITC-conjugated goat anti-mouse IgG (KPL, Kierkegaard \& Perry Laboratories, Inc., USA) was used as a secondary antibody. Cells were also incubated with the mouse IgG1 isotype control (eBioscience Inc., USA). Stained cells were analyzed with a FacsCalibur flow cytometer (Becton Dickinson, USA) with standard optical equipment using an argon ion laser tuned at $488 \mathrm{~nm}$. A total of 10,000 events were collected for each sample.

\section{Cutaneous delayed-type hypersensitivity}

On day 57 (15 days after the third immunization), all vaccinated calves were injected intradermally with $250 \mu \mathrm{g}$ OVA, $50 \mu \mathrm{g}$ bovine purified protein derivative (PPDb, Centro Panamericano de Zoonosis) according to the guidelines of SENASA, Argentina (22) and $0.1 \mathrm{~mL}$ PBS as negative control, using 28-gauge needles. Immediately before injection, the sites were shaved, cleaned and disinfected. Delayed type hypersensitivity (DTH) responses were determined as the difference in skin thickness between the time of inoculation and $72 \mathrm{~h}$ later. The results are reported as the mean increase in skin thickness in $\mathrm{mm} \pm$ standard deviation (SD) for each group. A 3-mm increase in skin thickness was considered to be a positive reaction.

\section{Serum antibodies against OVA}

Blood from cattle was collected on days $0,21,42$, and 57 to obtain serum for determining antibodies against OVA. Flat-bottomed 96-well polystyrene plates were coated with $50 \mu \mathrm{L} 2.5 \mathrm{mg} / \mathrm{mL}$ OVA in $0.05 \mathrm{M}$ sodium carbonate buffer, $\mathrm{pH} 9.6$ (coating buffer), overnight at $4^{\circ} \mathrm{C}$. The plates were washed three times with rinsing buffer (PBS containing $0.05 \%$ Tween 20 ) and then blocked with blocking buffer (PBS containing $0.05 \%$ Tween 20 and $10 \%$ dry skim milk) for 1 $\mathrm{h}$ at $37^{\circ} \mathrm{C}$. After washing, $50 \mu \mathrm{L}$ serum samples at different dilutions in blocking buffer was added and the plates were incubated for $1 \mathrm{~h}$ at $37^{\circ} \mathrm{C}$. Then, $50 \mu \mathrm{L} \mathrm{HRP}$-conjugated goat anti-bovine IgG (KPL) diluted 1:1000 was added to each well and the plates were further incubated for $1 \mathrm{~h}$ at $37^{\circ} \mathrm{C}$. Plates were washed three times after each step, substrate was added and plates were read at $490 \mathrm{~nm}$.

\section{Anti-OVA Ig isotypes}

Anti-OVA IgM, IgG1, IgG2, and IgG3 in sera of all immunized calves were detected by ELISA. The coating and blocking steps were performed as above. Sample and control sera (1:500) were incubated for $1 \mathrm{~h}$ at $37^{\circ} \mathrm{C}$. HRPconjugated sheep anti-bovine $\operatorname{lgM}, \lg G 1$ and $\lg \mathrm{g} 2$ (1:300) (Bethyl Labs Inc., USA) and unlabeled rabbit anti-bovine IgG3 diluted 1:500 (23) were added and incubated for $1 \mathrm{~h}$ at $37^{\circ} \mathrm{C}$. Then, HRP-conjugated goat anti-rabbit IgG (KPL) diluted 1:1000 was added to anti-lgG3 wells. Plates were washed three times after each incubation, substrate was added and plates were read at $490 \mathrm{~nm}$.

\section{Serological diagnosis of paratuberculosis}

Specific antibodies against paratuberculosis protoplasmic antigen (PPA; Allied Monitor Inc., USA) were detected by ELISA. Briefly, flat-bottomed 96-well polystyrene plates were coated with $2 \mu \mathrm{g}$ PPA in coating buffer. For adsorption of sera to avoid cross-reactions, $25 \mu \mathrm{L}$ sera was added to $100 \mu \mathrm{L}$ heat-inactivated M. phlei at an absorbance value of 1.0 at $600 \mathrm{~nm}$. The blocking step was performed as above. Sample and control sera (1:100) were incubated for $1 \mathrm{~h}$ at $37^{\circ} \mathrm{C}$. Then, $50 \mu \mathrm{L}$ HRP-conjugated goat anti-bovine IgG (KPL) diluted 1:1000 was added to each well and the plates were further incubated for $1 \mathrm{~h}$ at $37^{\circ} \mathrm{C}$. Plates were washed three times after each step, substrate was added and plates were read at $490 \mathrm{~nm}$. Internal ELISA controls were 5 negative sera with a mean absorbance value of 0.35 and infected sera with a mean absorbance value of 1.9.

\section{Statistical analysis}

Data were analyzed by either the Student $t$-test or oneway analysis of variance (ANOVA) followed by the Tukey multiple comparison test using STATISTIX 8.0 (Analytical Software, USA). Significance was determined as a $P$ value $<0.05$.

\section{Results}

\section{Characterization of the LAM extract}

The total carbohydrate yield obtained after LAM extraction was $15.7 \%$ of starting weight. Fractions that reacted strongly by ELISA with mAb CS-35 were pooled and concentrated by ultrafiltration, yielding $201.2 \mathrm{mg} / \mathrm{mL}$ (total 13.3 g) carbohydrate and $0.04 \mathrm{mg} / \mathrm{mL}$ (total $2.6 \mathrm{mg}$ ) protein. Concentrated LAM extract showed $0.82 \pm 0.04$ absorbance 
at $490 \mathrm{~nm}$ by ELISA with mAb CS-35, corresponding to $87 \%$ of positive control $M$. tuberculosis LAM (0.94 \pm 0.06 absorbance at $490 \mathrm{~nm}$ ). The LAM extract contained protein of similar apparent molecular mass (between 50 and 25 $\mathrm{kDa}$ ) and reactivity as $M$. tuberculosis LAM used as reference (Figure 1).

\section{Proliferation assays}

As regards the effect of LAM on the proliferation of peripheral cells, no differences between groups were detected on day 0. PBMC from the four groups responded to ConA on both day 0 and day 57. The OFL group showed a higher proliferation against ConA than the OF and $\mathrm{F}$ groups $(P=0.009)$ on day 57 (Figure 2a). Responses against OVA were significantly higher in the OFL than in the OF group $(P=0.001)$. As expected, an increase in specific OVA SI was detected in OFL and OF when that observed before immunization was compared to that observed 15 days af-
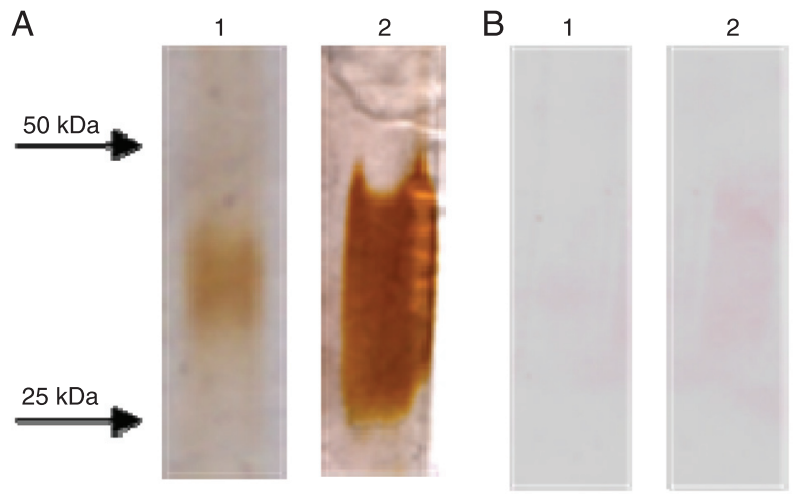

Figure 1. Characterization of the lipoarabinomannan (LAM) extract. A, Coomassie staining $12 \%$ SDS-PAGE electrophoresis gel. $B$, Immunoblot of the same gel using monoclonal antibody CS-35. Lane 1 = LAM extract; lane 2 = LAM of Mycobacterium tuberculosis.
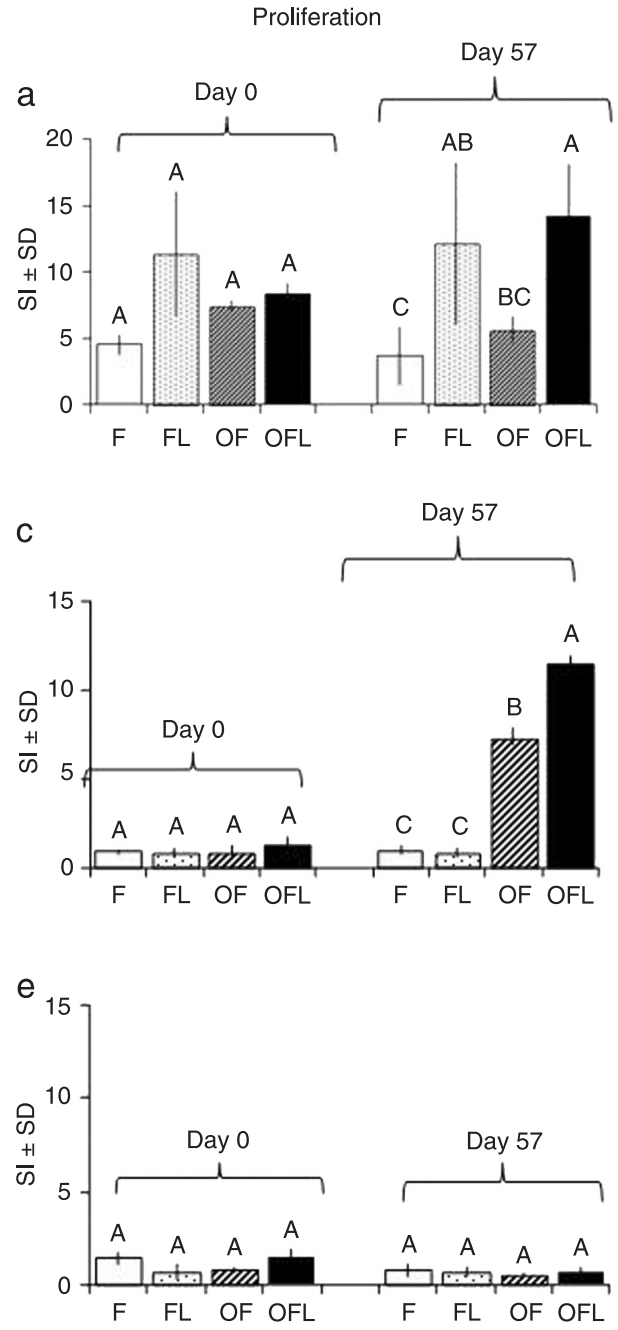

IFN- $\gamma$ production

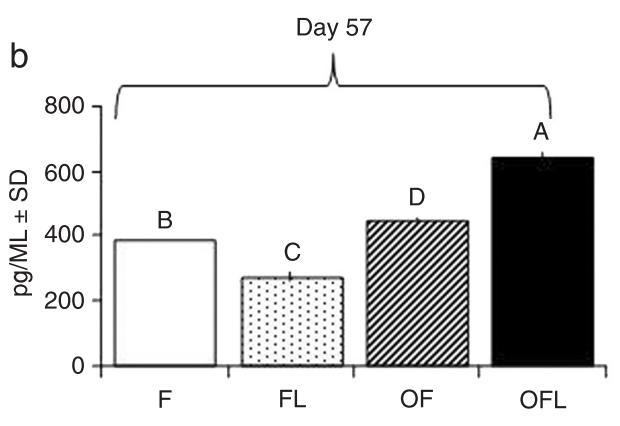

d

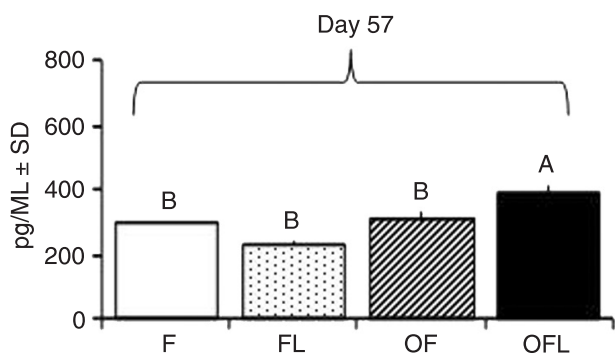

f

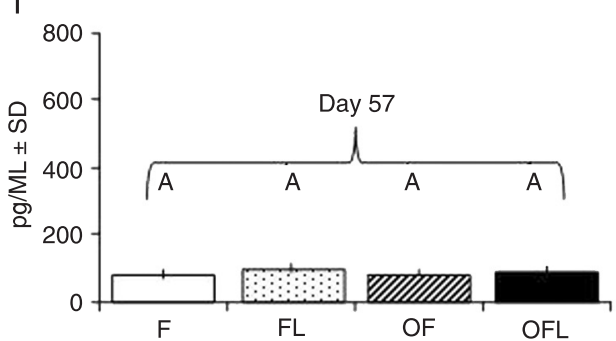

Figure 2. Effect of LAM on the cellular response. a, $c$ and $e$, PBMC proliferation. $b, d$ and $f$, IFN-y production. Data are reported as stimulation index $(\mathrm{SI}=$ mean $\mathrm{cpm}$ stimulated wells/mean cpm non-stimulated wells) or $\mathrm{pg} /$ $\mathrm{mL}$. $a$ and $b$, PBMC stimulated with ConA $(2.5 \mathrm{\mu g} /$ $\mathrm{mL}) ; c$ and $d$, PBMC stimulated with OVA $(250 \mu \mathrm{g} / \mathrm{mL})$; $e$ and $f$, PBMC stimulated with LAM $(250 \mu \mathrm{g} / \mathrm{mL})$. Error bars indicate standard deviation (SD) and different letters indicate significant differences between groups $(P<0.05$, ANOVA). Group $F$ $(N=5)$ was immunized with PBS and FIA; group FL (N = 3) with PBS, FIA and LAM; group OF $(\mathrm{N}=7)$ with OVA and FIA; group OFL $(\mathrm{N}=8)$ with FIA and LAM. LAM = lipoarabinomannan; $\mathrm{PBMC}=$ peripheral blood mononuclear cells; PBS = phosphate-buffered saline; FIA = Freund's incomplete adjuvant; OVA = ovalbumin. 
ter the last immunization (Figure 2c). When cells were stimulated with LAM, no significant differences were detected between groups (Figure 2e).

\section{IFN-Y detection in culture supernatants}

PBMC from OFL stimulated with ConA showed a significantly higher IFN-y production than those from the OF group $(P=0.01$; Figure 2b). Similarly, PBMC stimulated with OVA showed significantly higher IFN-y production in the OFL than in the OF group $(P=0.03$; Figure $2 \mathrm{~d}$ ). When cells were stimulated with LAM, no significant differences were detected between groups (Figure 2f). These results suggest that LAM is an immunomodulator capable of increasing IFN-y production.
Table 1. Expression of $\mathrm{IgG}^{+}, \mathrm{CD}^{+}, \mathrm{CD}^{+}$, and $\mathrm{CD} 25^{+}$in bovine peripheral blood mononuclear cells before and 15 days after the third immunization.

\begin{tabular}{lrcrc}
\hline Group & \multicolumn{1}{c}{$\mathrm{IgG}^{+}$} & $\mathrm{CD}^{+}$ & $\mathrm{CD}^{+}$ & $\mathrm{CD}^{+} 5^{+}$ \\
\hline Pre-immunization & $12.64 \pm 1.58$ & $23.73 \pm 13.06$ & $11.3 \pm 2.01$ & $2.00 \pm 0.90$ \\
F & $9.25 \pm 6.51$ & $18.38 \pm 0.32$ & $6.96 \pm 2.91$ & $3.20 \pm 0.40$ \\
FL & $8.10 \pm 4.90$ & $11.10 \pm 5.00$ & $9.10 \pm 5.20$ & $2.60 \pm 0.03$ \\
OF & $13.08 \pm 5.75$ & $19.50 \pm 9.23$ & $9.61 \pm 1.06$ & $6.25 \pm 0.96$ \\
OFL & $17.69 \pm 3.60$ & $20.34 \pm 4.22$ & $10.73 \pm 4.92$ & $11.15 \pm 3.20^{*}$ \\
\hline
\end{tabular}

Data are reported as percent \pm SD. Pre-immunization values correspond to all animals before being assigned to each group. Group $F(N=5)$ was immunized with PBS and FIA; group FL $(\mathrm{N}=3)$ with PBS, FIA and LAM; group OF $(\mathrm{N}=7)$ with OVA and FIA; group OFL $(\mathrm{N}=8)$ with OVA, FIA and LAM. FIA = Freund's incomplete adjuvant; PBS = phosphate-buffered saline; $\mathrm{LAM}=$ lipoarabinomannan; OVA = ovalbumin. ${ }^{*} \mathrm{P}<0.05$ compared to other groups (ANOVA).

\section{Cell subpopulations}

$\mathrm{IgG}^{+}, \mathrm{CD}^{+}, \mathrm{CD}^{+}$, and $\mathrm{CD} 25^{+}$cell subpopulations from PBMC were evaluated before and 15 days after treatment. After immunization, $\mathrm{IgG}^{+}, \mathrm{CD}^{+}$, and $\mathrm{CD}^{+}$cell counts showed similar levels of expression in all groups. Remarkably, expression of CD25 in the OF and OFL groups was higher after immunization than before $(P=0.003$ and $P=$ 0.01 , respectively). Comparison between groups after the third immunization showed a higher CD25 expression ( $P$ $=0.01$ ) in OFL than in OF, FL, and F (Table 1).

\section{Delayed type hypersensitivity}

DTH reactions against OVA were measured in order to determine whether LAM was able to modify the in vivo response to this protein antigen. All calves gave negative reactions to the intradermal skin test using OVA (Table 2).

\section{Specific humoral immune response}

Specific anti-OVA titers and IgG isotypes were significantly higher $(P<0.05)$ after the immunizations than on day 0 for both the OFL and OF groups. This indicates that the immunization protocol used to induce specific antibody responses was successful. Log titer antibody responses to OVA did not show significant differences between OVA immunized groups on days 21, 42, and 57 (Figure 3). The specific anti-lgM response did not differ between groups and was lower than IgG isotype responses. No significant differences were observed in the specific isotype responses between the OF and OFL groups (Figure 4).

\section{Tuberculosis and paratuberculosis diagnosis}

DTH reactions against PPDb were evaluated to identify a possible interference with the diagnosis of this tuberculosis and negative reactions were detected in all calves (Table 2).

Serum-specific anti-PPA responses showed negative results on days 0 and 57 for all the groups analyzed
Table 2. Delayed-type hypersensitivity immune response in cattle.

\begin{tabular}{lccc}
\hline Group & PBS & OVA & PPDb \\
\hline F & 0 & 0 & $0.4 \pm 0.5$ \\
FL & 0 & ND & $0.9 \pm 0.7$ \\
OF & $0.3 \pm 0.6$ & $0.5 \pm 0.5$ & $0.5 \pm 0.5$ \\
OFL & $1.0 \pm 0.9$ & $0.3 \pm 0.6$ & $0.5 \pm 0.7$ \\
\hline
\end{tabular}

Data are reported as mean increase in skin thickness $(\mathrm{mm}) \pm \mathrm{SD}$ on day $60(\mathrm{P}<0.05$, ANOVA). ND = not determined. Group $\mathrm{F}(\mathrm{N}=$ $5)$ was immunized with PBS and FIA; group $F L(N=3)$ with PBS, FIA and LAM; group OF $(N=7)$ with OVA and FIA; group OFL (N $=8$ ) with OVA, FIA and LAM. FIA = Freund's incomplete adjuvant; $\mathrm{PBS}=$ phosphate-buffered saline; $\mathrm{LAM}=$ lipoarabinomannan; OVA = ovalbumin; $\mathrm{PPDb}=$ bovine purified protein derivative.

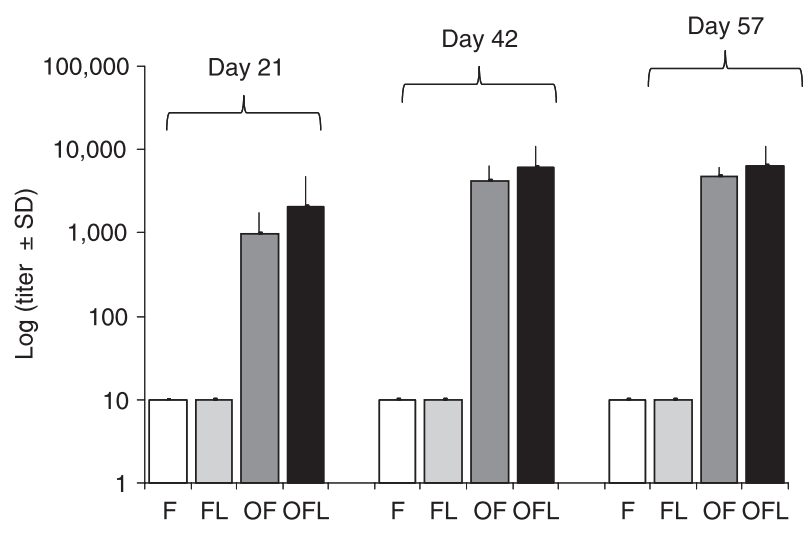

Figure 3. Logarithms of anti-OVA titers measured by ELISA on days 21,42 , and 57 . Error bars indicate the standard deviation (SD) using ANOVA. Group $F(N=5)$ was immunized with PBS and FIA; group FL $(\mathrm{N}=3)$ with PBS, FIA and LAM; group OF $(\mathrm{N}=$ 7) with OVA and FIA; group OFL $(\mathrm{N}=8)$ with FIA and LAM. PBS = phosphate-buffered saline; FIA = Freund's incomplete adjuvant; $\mathrm{LAM}=$ lipoarabinomannan; OVA = ovalbumin. 
(Table 3). This indicates that LAM inoculation did not induce cross-reactions with PPA used for the diagnosis of paratuberculosis.

\section{Discussion}

The present study was conducted in order to evaluate the effect of LAM addition to FIA inoculated with a noninfectious antigen, to improve the immune response in calves. Several studies have shown that LAM is a highly immunogenic molecule $(24,25)$, which has been related to mycobacterial pathogenesis $(12,26)$. Then, LAM has been proposed as immunomodulator $(12,16,27,28)$.

Investigations in humans and animals have used FIA in vaccine formulation to induce persistent, high-titer protective humoral immune responses $(4,7)$. In fact, the use of an oil adjuvant in foot- and mouth-disease vaccine has allowed an increase in the interval between immunizations. Actually, the use of FIA in our immunization protocol is supported by the fact that it is included in commercial formulations assigned to bovine (29) and human vaccines (30).

We chose OVA as a T-dependent antigen because it has been previously reported to elicit cellular and humoral immune responses in calves and mice $(4,31)$. The OVA doses and the immunization protocol used in our study were based on experiments carried out in cattle by Hernández et al. (4). As expected, in our model, OVA antigen induced high antibody titers with a major IgG response after only one dose.

With our extraction methodology, characterization of crude LAM was similar to that obtained from M. tuberculosis by Hamasur et al. (18).

The stimulation of a specific cell immune response is important to increase protection against intracellular pathogens (28). Our study showed that LAM increases the specific cell immune response, evaluated by lymphoproliferation, compared to vaccination with antigen with incomplete Freund's adjuvant alone. Likewise, immunization with LAM as an immunomodulator induced a seven times higher proliferation than the preimmunization value and than that reported by Sun et al. (32) using OVA with other adjuvants. Similar results have been reported with other oil adjuvants compared to cationic liposomes in a bovine model (33). We showed here an increase in proliferation to ConA in the OFL group, indicating that stimulation with LAM affects both antigen-specific and -non-specific lymphocytes. In the same way, we detected an increase in IFN- $y$ production in LAM-treated animals. These results are in agreement with other experiments in which LAM from $M$. bovis induced an increase in IFN-Y production in a mouse model (34). IFN-Y production involves macrophage and lymphocyte activation and is associated with the Th1 response in cattle $(3,33)$. As demonstrated by flow cytometry analysis, our experiments showed an increase in $\mathrm{CD} 25^{+}$cells. Some investigators have demonstrated a proliferative immune response by bovine $\mathrm{CD} 4^{+} \mathrm{T}$ cells to soluble mycobacterial antigens linked with a markedly increased expression of CD25 (35). The functional relevance and correlation with in vitro findings remain unclear. In our model, the increase in CD25 could be related to the immunomodulation induced by glycolipids. The CD4/CD8 ratio detected in our experiments remained within the normal values previously reported for cattle (36). This seems to indicate that LAM addition does not modify the proportion of these subpopulations. We could not detect OVA-specific DTH responses. Different results have been previously reported by Hernández et al. (4) in cattle inoculated with cell walls of M. phlei and OVA. Since, in our model, we used purified LAM, we can suggest that the use of LAM does not cause the same effect

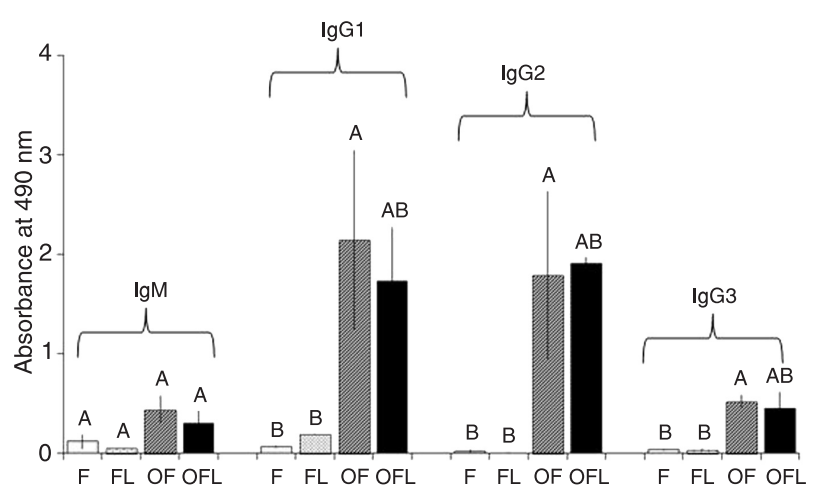

Figure 4. Anti-OVA IgM, IgG1, IgG2, and IgG3 were measured by ELISA on day 57 after the initial immunization. Absorbance values of $\operatorname{lgM}$, IgG1, IgG2, and IgG3 responses to OVA are reported as means $\pm S D$. Different letters indicate significant differences among groups $(P<0.05$, ANOVA). Group $F(N=5)$ was immunized with PBS and FIA; group FL $(\mathrm{N}=3)$ with PBS, FIA and LAM; group OF $(\mathrm{N}=7)$ with OVA and FIA; group OFL ( $=$ 8) with FIA and LAM. PBS = phosphate-buffered saline; FIA = Freund's incomplete adjuvant; LAM = lipoarabinomannan; OVA = ovalbumin.

Table 3. Specific antibodies against paratuberculosis protoplasmic antigen.

\begin{tabular}{lcc}
\hline Group & $\begin{array}{c}\text { Day 0 } \\
\text { (A at } 490 \mathrm{~nm} \pm \mathrm{SD})\end{array}$ & $\begin{array}{c}\text { Day } 57 \\
(\text { A at } 490 \mathrm{~nm} \pm \mathrm{SD})\end{array}$ \\
\hline $\mathrm{F}$ & $0.19 \pm 0.03$ & $0.18 \pm 0.04$ \\
$\mathrm{FL}$ & $0.16 \pm 0.08$ & $0.13 \pm 0.03$ \\
OF & $0.18 \pm 0.08$ & $0.14 \pm 0.02$ \\
OFL & $0.20 \pm 0.14$ & $0.17 \pm 0.12$ \\
\hline
\end{tabular}

Data are reported as absorbance (A) at $490 \mathrm{~nm} \pm$ SD (ANOVA). Internal ELISA controls were 5 negative sera $(A=0.35)$ and infected sera $(A=1.90)$. Group $F(N=5)$ was immunized with PBS and FIA; group FL $(\mathrm{N}=3)$ with PBS, FIA and LAM; group OF $(\mathrm{N}=$ 7 ) with OVA and FIA; group OFL $(\mathrm{N}=8)$ with OVA, FIA and LAM. $\mathrm{PBS}=$ phosphate-buffered saline; FIA = Freund's incomplete adjuvant; LAM = lipoarabinomannan; OVA = ovalbumin. 
as mycobacterial cell walls.

The study of serum immunoglobulins by the evaluation of relative concentration and isotypic composition is useful for testing immunomodulators (37). Our results show that modulation of LAM induced high titers of OVA-specific antibodies after the first immunization in cattle. These levels were increased in the second dose and remained after the third immunization, in agreement with results published by Heriazon et al. (3) using OVA with saponins. A relationship between the isotypes produced and the immune response profile in cattle has been previously established (38). Similarly, in sheep, an increase in the specific production of IgG2 isotype and IFN-y has been detected when using a recombinant protein of Taenia ovis and FIA as adjuvant (39). Our results indicate that the serum response against OVA predominantly involved IgG1 and IgG2 and, to a lesser extent, IgG3 but no differences were detected, probably for the high dispersion found between animals belonging to the OFL group. The measurements of cutaneous hypersensitivity produced against PPD and ELISA-PPA are the methods most frequently used in Argentina for the

\section{References}

1. Cox JC, Coulter AR. Adjuvants - a classification and review of their modes of action. Vaccine 1997; 15: 248-256.

2. Stills HF Jr. Adjuvants and antibody production: dispelling the myths associated with Freund's complete and other adjuvants. ILAR J 2005; 46: 280-293.

3. Heriazon A, Thompson KA, Wilkie BN, Mathes-Sears W, Quinton M, Mallard BA. Antibody to ovalbumin and delayedtype hypersensitivity to Candida albicans and mycobacteria in lactating Holstein cows using Quil A or Freund's complete adjuvant. Vet Immunol Immunopathol 2009; 127: 220-227.

4. Hernández A, Yager JA, Wilkie BN, Leslie KE, Mallard BA. Evaluation of bovine cutaneous delayed-type hypersensitivity (DTH) to various test antigens and a mitogen using several adjuvants. Vet Immunol Immunopathol 2005; 104: 45-58.

5. Wedlock DN, Denis M, Painter GF, Ainge GD, Vordermeier $H M$, Hewinson RG, et al. Enhanced protection against bovine tuberculosis after coadministration of Mycobacterium bovis BCG with a Mycobacterial protein vaccine-adjuvant combination but not after coadministration of adjuvant alone. Clin Vaccine Immunol 2008; 15: 765-772.

6. Aucouturier J, Dupuis L, Deville S, Ascarateil S, Ganne V. Montanide ISA 720 and 51: a new generation of water in oil emulsions as adjuvants for human vaccines. Expert Rev Vaccines 2002; 1: 111-118.

7. Miller LH, Saul A, Mahanty S. Revisiting Freund's incomplete adjuvant for vaccines in the developing world. Trends Parasitol 2005; 21: 412-414.

8. Cobo ER, Morsella C, Cano D, Cipolla A, Campero CM. Immunization in heifers with dual vaccines containing Tritrichomonas foetus and Campylobacter fetus antigens using systemic and mucosal routes. Theriogenology 2004; 62: 1367-1382. diagnosis of tuberculosis and paratuberculosis in cattle. Even if cross-reactions have been described with other mycobacteria (40), we did not detect positive reactions in LAM-treated groups.

Our study provides original data on the effect of LAM on the lymphoproliferative response, IFN-y production, the humoral immune response, and isotypes involved against OVA in cattle.

We demonstrated that LAM, at the dose, route and immunization protocol used in the present study, in combination with FIA, is able to improve specific cell immune response evaluated by lymphoproliferation and IFN-Y production by at least 50 and $25 \%$, respectively, in cattle.

\section{Acknowledgments}

We thank Dr. Ana M. Jar for her kind help and valuable suggestions, VMD Liliana Ramayo and student María Laura Fortuny for their technical assistance. Research supported by UBACyT, Project VE023 (\#2008-2011) and BID PICT (\#2010-2672).

9. Jensen FC, Savary JR, Diveley JP, Chang JC. Adjuvant activity of incomplete Freund's adjuvant. Adv Drug Deliv Rev 1998; 32: 173-186.

10. Hunter SW, Brennan PJ. Evidence for the presence of a phosphatidylinositol anchor on the lipoarabinomannan and lipomannan of Mycobacterium tuberculosis. J Biol Chem 1990; 265: 9272-9279.

11. Nigou J, Gilleron M, Puzo G. Lipoarabinomannans: from structure to biosynthesis. Biochimie 2003; 85: 153-166.

12. Briken V, Porcelli SA, Besra GS, Kremer L. Mycobacterial lipoarabinomannan and related lipoglycans: from biogenesis to modulation of the immune response. Mol Microbiol 2004; 53: 391-403.

13. Guerardel $Y$, Maes E, Elass E, Leroy $Y$, Timmerman $P$, Besra GS, et al. Structural study of lipomannan and lipoarabinomannan from Mycobacterium chelonae. Presence of unusual components with alpha 1,3-mannopyranose side chains. J Biol Chem 2002; 277: 30635-30648.

14. Bhattacharjee S, Majumder N, Bhattacharyya P, Bhattacharyya S, Majumdar S. Immunomodulatory role of arabinosylated lipoarabinomannan on Leishmania donovani infected murine macrophages. Indian J Biochem Biophys 2007; 44: 366-372.

15. Barrow WW, de Sousa JP, Davis TL, Wright EL, Bachelet M, Rastogi N. Immunomodulation of human peripheral blood mononuclear cell functions by defined lipid fractions of $\mathrm{My}$ cobacterium avium. Infect Immun 1993; 61: 5286-5293.

16. Smit JJ, Van Loveren H, Hoekstra MO, Schijf MA, Folkerts G, Nijkamp FP. Mycobacterium vaccae administration during allergen sensitization or challenge suppresses asthmatic features. Clin Exp Allergy 2003; 33: 1083-1089.

17. Sayers I, Severn W, Scanga CB, Hudson J, Le Gros G, Harper JL. Suppression of allergic airway disease using 
mycobacterial lipoglycans. J Allergy Clin Immunol 2004; 114: 302-309.

18. Hamasur B, Kallenius G, Svenson SB. A new rapid and simple method for large-scale purification of mycobacterial lipoarabinomannan. FEMS Immunol Med Microbiol 1999; 24: 11-17.

19. Dubois M, Gilles K, Hamilton JK, Rebers PA, Smith F. A colorimetric method for the determination of sugars. Nature 1951; $168: 167$.

20. Bradford MM. A rapid and sensitive method for the quantitation of microgram quantities of protein utilizing the principle of protein-dye binding. Anal Biochem 1976; 72: 248-254.

21. Deringer JR, Ely RJ, Monday SR, Stauffacher CV, Bohach GA. Vbeta-dependent stimulation of bovine and human $T$ cells by host-specific staphylococcal enterotoxins. Infect Immun 1997; 65: 4048-4054.

22. SENASA Argentina. Programa nacional de control y erradicación de la tuberculosis bovina. http://www.senasa.gov.ar/ contenido. php?to=n\&iN = 858\&io=15899.

23. Mundo SL, Fontanals AM, Garcia M, Durrieu M, Alvarez E, Gentilini ER, et al. Bovine IgG1 antibodies against Mycobacterium avium subsp. paratuberculosis protein p34-cx improve association of bacteria and macrophages. Vet Res 2008; 39: 6.

24. Koets AP, Rutten VP, de Boer M, Bakker D, Valentin-Weigand $P$, van Eden W. Differential changes in heat shock protein-, lipoarabinomannan-, and purified protein derivative-specific immunoglobulin $\mathrm{G} 1$ and $\mathrm{G} 2$ isotype responses during bovine Mycobacterium avium subsp. paratuberculosis infection. Infect Immun 2001; 69: 1492-1498.

25. Watanabe Y, Watari E, Matsunaga I, Hiromatsu K, Dascher CC, Kawashima T, et al. BCG vaccine elicits both T-cell mediated and humoral immune responses directed against mycobacterial lipid components. Vaccine 2006; 24: 57005707.

26. Flynn JL, Chan J. Immunology of tuberculosis. Annu Rev Immunol 2001; 19: 93-129.

27. Ito T, Hasegawa A, Hosokawa H, Yamashita M, Motohashi $\mathrm{S}$, Naka T, et al. Human Th1 differentiation induced by lipoarabinomannan/lipomannan from Mycobacterium bovis BCG Tokyo-172. Int Immunol 2008; 20: 849-860.

28. Guenin-Mace L, Simeone R, Demangel C. Lipids of pathogenic Mycobacteria: contributions to virulence and host immune suppression. Transbound Emerg Dis 2009; 56: 255-268.

29. Robiolo B, La Torre J, Maradei E, Beascoechea CP, Perez A, Seki $C$, et al. Confidence in indirect assessment of foot- and-mouth disease vaccine potency and vaccine matching carried out by liquid phase ELISA and virus neutralization tests. Vaccine 2010; 28: 6235-6241.

30. Roman F, Vaman T, Gerlach B, Markendorf A, Gillard P, Devaster JM. Immunogenicity and safety in adults of one dose of influenza A H1N1v 2009 vaccine formulated with and without AS03A-adjuvant: preliminary report of an observerblind, randomised trial. Vaccine 2010; 28: 1740-1745.

31. Habjanec L, Halassy B, Tomasic J. Comparative study of structurally related peptidoglycan monomer and muramyl dipeptide on humoral IgG immune response to ovalbumin in mouse. Int Immunopharmacol 2010; 10: 751-759.

32. Sun HX, Ye YP, Pan HJ, Pan YJ. Adjuvant effect of Panax notoginseng saponins on the immune responses to ovalbumin in mice. Vaccine 2004; 22: 3882-3889.

33. Vordermeier HM, Dean GS, Rosenkrands I, Agger EM, Andersen P, Kaveh DA, et al. Adjuvants induce distinct immunological phenotypes in a bovine tuberculosis vaccine model. Clin Vaccine Immunol 2009; 16: 1443-1448.

34. Rosenkrands I, Agger EM, Olsen AW, Korsholm KS, Andersen CS, Jensen KT, et al. Cationic liposomes containing mycobacterial lipids: a new powerful Th1 adjuvant system. Infect Immun 2005; 73: 5817-5826.

35. Waters WR, Rahner TE, Palmer MV, Cheng D, Nonnecke BJ, Whipple DL. Expression of L-Selectin (CD62L), CD44, and CD25 on activated bovine T cells. Infect Immun 2003; 71: 317-326.

36. Seo KS, Lee SU, Park YH, Davis WC, Fox LK, Bohach GA. Long-term staphylococcal enterotoxin $\mathrm{C} 1$ exposure induces soluble factor-mediated immunosuppression by bovine CD4+ and CD8+ T cells. Infect Immun 2007; 75: 260-269.

37. Berghaus LJ, Corbeil LB, Berghaus RD, Kalina WV, Kimball RA, Gershwin LJ. Effects of dual vaccination for bovine respiratory syncytial virus and Haemophilus somnus on immune responses. Vaccine 2006; 24: 6018-6027.

38. Estes DM, Brown WC. Type 1 and type 2 responses in regulation of $\mathrm{Ig}$ isotype expression in cattle. Vet Immunol Immunopathol 2002; 90: 1-10.

39. Rothel JS, Corner LA, Lightowlers MW, Seow HF, McWaters $P$, Entrican G, et al. Antibody and cytokine responses in efferent lymph following vaccination with different adjuvants. Vet Immunol Immunopathol 1998; 63: 167-183.

40. Waters WR, Palmer MV, Thacker TC, Payeur JB, Harris NB, Minion FC, et al. Immune responses to defined antigens of Mycobacterium bovis in cattle experimentally infected with Mycobacterium kansasii. Clin Vaccine Immunol 2006; 13: 611-619. 